\title{
educação

\section{“O pré-escolar faz a diferença?" Políticas educativas na educação de infância e práticas pedagógicas}

\author{
Manuela Ferreira ${ }^{\mathrm{I}}$ \\ Universidade do Porto, Portugal
}

\author{
CATARINA TOMÁS \\ Instituto Politécnico de Lisboa, Portugal
}

\begin{abstract}
A identificação de práticas sociopedagógicas tendencialmente reprodutoras da forma escolar, e de currículos de coleção e modos de transmissão pedagógica formais que enfatizam a literacia, a numeracia e a ciência apontam para a reconfiguração da Educação de Infância como contexto de crescente escolarização e alunização precoce das crianças e como estratégia de prevenção socioeducativa do insucesso escolar. $\mathrm{Na}$ interlocução entre Sociologia da Infância, Sociologia da Educação e Ciências da Educação, analisa-se o rumo das recentes mudanças políticas da Educação de Infância no quadro internacional e nacional, recuando aos anos 90, e alguns dos seus efeitos ao nível das práticas pedagógicas. A reconstituição deste trajeto assenta na análise crítica de documentos oficiais, nomeadamente as novas Orientações Curriculares para a Educação Pré-Escolar (2016), e de observações realizadas em Jardins de Infância, públicos e privados, entre 2015 e 2017, em Portugal.
\end{abstract}

Palavras-chave: Educação de infância; Políticas educativas; Práticas pedagógicas; Orientações curriculares para a educação pré-escolar

\section{IN T RODUÇ ÃO}

“O pré-escolar faz a diferença?" é a interrogação de um artigo publicado numa conhecida revista portuguesa, Visão (2016), em que são divulgados alguns dos efeitos positivos do aumento da frequência da Educação PréEscolar (EPE) nos resultados obtidos pelos/ as alunos/as, por exemplo, ao nível dos scores PISA Leitura ${ }^{1}$ e menor percentagem de retenções escolares, bem como dos benefícios que crianças oriundas das classes mais desfavorecidas assim alcançam. A importância social da EPE, sublinhada na resposta de modo prospetivo e enviesado, enfatiza sobretudo os resultados académicos, apresentando-a como se de uma espécie de solução se tratasse para obstar a um futuro hipotecado pelo

\footnotetext{
${ }^{1} \mathrm{O}$ Programme for International Student Assessment (PISA) é desenvolvido pela OCDE e tem como objetivo avaliar os/as estudantes de 15 anos em competências de Leitura, de Matemática ou de Ciências. Cf. http://www.oecd.org/pisa/ e Projeto de investigação aQeduto: Avaliação, qualidade e equidade em educação. Consultar em: http://www.aqeduto.pt/
} 
insucesso escolar precoce. Esta mesma ideia, igualmente replicada em jornais nacionais de grande tiragem, avoluma um discurso mediático que parece refratar uma perspetiva tornada dominante acerca dos propósitos da Educação, em geral, e da Educação de Infância (EI) em particular, contribuindo também, deste modo, para a sua difusão, normalização e naturalização.

Nesta lógica, pode dizer-se que um dos sentidos possíveis da resposta afirmativa à pergunta “O pré-escolarfaz a diferença?” remete para uma conceção da EPE como estratégia de prevenção socioeducativa, na qual aquela diferença se forja pela aposta na transmissão de um currículo cujos conteúdos são vistos como úteis no contexto de uma economia global e de uma ordem pautada pelo individualismo e competitividade (Lima, 2017). Investir política e socialmente na EPE do presente, mas por via de processos de escolificação (Garnier, 2016; Ferreira \& Tomás, 2017a,b), que já têm em mira a performatividade académica, torna-se, assim, um modo de reabilitar, ressignificar e rejuvenescer a velha teoria do capital humano (Motta, 2012) e de embaciar as desigualdades de uma sociedade que a educação não pode compensar.

Com efeito, discursos radicados na história e na tradição pedagógica da EI e/ou em prol dos direitos da criança aparecem hoje mesclados, pulverizados e/ou reinterpretados num outro discurso, que tem vindo a impor-se na EI em nome das novas exigências colocadas pela sociedade neoliberal, como é o caso do discurso sobre a qualidade, a avaliação e o sucesso académico. Em termos esquemáticos detetam-se, assim, duas orientações com forças de sentido contrário no campo da EI, tanto em termos legislativos como das práticas no Jardim de Infância (JI): por um lado, os discursos das crianças como sujeitos competentes com direitos de participação e, por outro, os discursos neoliberais assentes na apologia da flexibilidade, da escolhaindividual, da prestação de contas [accountability] e de uma precoce promoção e valorização do desenvolvimento de determinadas competências (Kjørholt \& Seland, 2012). Este último discurso representa uma forte orientação de mercado, que constrói a ideia de criança como consumidora e utente, e como investimento económico indireto a longo prazo, ou seja, como um capital humano projetado numa futura trabalhadora, útil e rentável; cidadã contribuinte para a prosperidade nacional.

Corresponde a esta ideia uma outra: a de JI como espaço educativo cada vez mais pressionado a orientar-se para uma noção de qualidade concordante com a sua curricularização e práticas pedagógicas escolarizantes, aferíveis mediante a apresentação de resultados da iniciação das crianças nas aprendizagens académicas ulteriores, reduzindose distâncias entre a escola e o/a aluno/a, o/a professor/a e a instrução, a ponto de alguns autores questionarem se o JI não estará está a transformar-se num $1^{\circ}$ CEB (Bassok, Latham, \& Rorem, 2016; Ferreira \& Tomás, 2016, 2017; Garnier, 2016).

Instigado pela interrogação "O pré-escolar faz a diferença?”, e referenciado à interlocução entre Sociologia da Infância, Sociologia da Educação e Ciências da Educação, este artigo visa compreender o rumo das recentes mudanças políticas da EI no quadro internacional e nacional, sobretudo a partir dos anos 90 do século XX, e alguns dos seus reflexos ao nível das práticas pedagógicas.

A reconstituição deste trajeto assenta na análise de documentos oficiais produzidos pelo Ministério da Educação (ME) - legislação e Orientações Curriculares para a Educação Pré-Escolar (OCEPE, 2016 - Despacho n. ${ }^{\circ}$ 9180/2016) - e de observações realizadas em JI, públicos e privados, entre 2015 e 2017, 
abrangendo uma heterogeneidade de contextos socioeconómicos, geográficos, culturais e organizacionais $^{2}$. Trata-se de identificar os principais marcos e tendências que parecem estar a colonizar o campo da EI nas últimas décadas e de perscrutar a sua apropriação local por via de mudanças nas práticas das/ os educadoras/es de infância, no papel das crianças e nas funções do JI, interrogando os seus sentidos de modo a contribuir para a desinstrumentalização da EI.

\section{QUANDO A QUALIDADE, A EFICÁCIA E A EXCELÊNCIA CHEGAM À EDUCAÇÃO DE INFÂNCIA}

Os anos 80 do século $\mathrm{XX}$, sociológica e educativamente caraterizados como um tempo de transição paradigmática na ordem internacional (Ball, 2001; Santos, 1991; Stoer, 2002), contextualizam três acontecimentos marcantes no campo da EI: 1) a comemoração do Ano Internacional da Criança, em 1979, e, dez anos depois, a ratificação quase universal da Convenção dos Direitos das Crianças (ONU, 1989), que consagra os seus direitos de provisão, proteção e participação; 2) a emergência e constituição da Sociologia da Infância, em rutura com as perspetivas médicopsicológicas dominantes na pesquisa sobre as crianças, e a atual multiplicação de estudos multidisciplinares subscritores das premissas do paradigma das crianças como atores sociais
(James \& Prout, 1990); 3) a institucionalização socioeducativa da pequena infância, entretanto tornada norma nas sociedades ocidentais, e a crescente penetração do discurso da qualidade na EPE, traduzindo a pressão exercida pelas políticas neoliberais sobre a educação e o sistema escolar, e os seus métodos.

Com efeito, no caso europeu, Sahlberg (2010) identifica um conjunto de tendências na educação que desenham uma viragem - e uma viagem transnacional geradora de alterações nacionais e locais - discernível em torno das lógicas neoliberais, em que se salientam o estreitamento do currículo para potenciar o "conhecimento válido" (numeracia, literacia e ciência), a pressão para a prestação de contas e a estandardização dos resultados através do estabelecimento de rankings e de medidas quantitativas que classificam e ordenam visando fomentar a competitividade económica (Ball, 2001; Moss, 2015) - veja-se a produção e divulgação de relatórios por organismos transnacionais (European Commission/EACEA/Eurydice, 2016; OECD, 2017; UNESCO, 2015; Banco Mundial $^{3}$; UNICEF ${ }^{4}$, etc.) que têm potenciado a comparação entre países relativamente à EI, desde o acesso à frequência, à qualidade, ao orçamento disponibilizado, entre outros aspetos, e o uso de dispositivos e instrumentos de avaliação da qualidade do JI 'mundo fora' (e.g. Escala de Avaliação do Ambiente em

\footnotetext{
${ }^{2}$ A seleção dos seis JI não obedeceu a critérios sociográficos pré-definidos: dependeu da aceitação, pelas educadoras contatadas, da realização da observação participante nas suas salas. O trabalho de campo realizou-se em 2015, 2016 e 2017 em JI públicos e um privado, em Lisboa e no Porto, e a sua duração variou, com observações contínuas e sistemáticas, em uns casos, diariamente durante quatro meses, e, em outros, semanal ou quinzenalmente durante o ano letivo. As educadoras tinham, em média, 17 anos de experiência de trabalho. Os grupos de crianças caracterizaram-se pela heterogeneidade de idades, podendo coexistir crianças com idades entre os 3-6 anos - no JIA (2015): 18 crianças de 5 anos, 7 meninas e 11 meninos; no JIB (2016): 20 crianças entre os 3-5 anos, 11 meninos e 9 meninas; no JIC (2017): 20 crianças entre os 4-6 anos, 7 meninos e 13 meninas; no JID (2015): 25 crianças entre os 4-6 anos, 11 meninos e 14 meninas. No respeito ético da pesquisa com crianças, apesar de formalizado o consentimento informado com os adultos por elas responsáveis e com as próprias, e de este ter sido renegociado com as crianças sempre que foi necessário, tal como é prática corrente no âmbito da Sociologia da Infância, estas, as/os suas/seus educadoras/es de infância e instituição não são identificados, tendo-se procurado retirar do texto todas as informações geradoras de pseudoanonimato.
}

\footnotetext{
${ }^{3}$ Consultar https://openknowledge.worldbank.org/discover?query=early\%20childhood

${ }^{4}$ Consultar https://data.unicef.org/resources/early-childhood-education/
} 
Educação de Infância (ECERS-R), Harms, Clifford, \& Cryer, 1998) $)^{5}$. Trata-se de um processo de globalização hegemónica, existindo pressões políticas e económicas oriundas das várias escalas, que se exercem de fora para dentro e de cima para baixo, para que a EI aumente o seu nível de qualidade, focando-se na obtenção de resultados de aprendizagens úteis a uma escolarização bem sucedida, que assim espelhará os graus de eficácia e eficiência alcançados e os patamares de produtividade dos/as educadores/as.

Não obstante, começam a fazer-se sentir vozes críticas e alternativas. Moss et al. (2016) criticam a visão uniforme, monocultural e limitada do relatório International Early Learning and Well-being Study ${ }^{6}$ da OCDE, uma avaliação transnacional que defende que avaliar as crianças de cinco anos pode contribuir para melhorar o seu desempenho posterior nos testes PISA, e a desconsideração da OCDE face: a um movimento internacional, académico e social que contesta esta visão dominante da EI; às diferenças entre países na comparação de resultados; à ampla rede de relações socioculturais nas quais as crianças circulam, além do JI; a uma visão estreita da noção de ambiente educativo e meio ambiente, restrita à sala de atividades.

Outro dos efeitos das políticas neoliberais refere-se a transformações nos objetivos e finalidades da EI, e num currículo e pedagogia tendentes a acentuar a sua pré-escolarização e a produzir crianças como alunos/as préescolares, conforme atestam estudos recentes em França (Garnier, 2016), EUA (Bassok et al., 2016), Noruega (Kjørholt \& Seland, 2012; Otterstad \& Braathe, 2016), Suécia (Halldén, 2012) ou Brasil (Losso \& Marchi, 2011).
Uma maior atenção dada à sequencialidade educativa e à transição das crianças do JI para o $1^{\circ} \mathrm{CEB}$, e do que isso acarreta para um quotidiano do JI organizado em conformidade, sobretudo com o ensino formalizado de determinados conteúdos curriculares, parecem ter-se disseminado como sendo as principais preocupações das agências supranacionais, dos governos, das famílias, das direções das organizações socioeducativas e dos/as educadores/as de infância. Pode então dizer-se que, no mundo ocidental, um maior investimento nas políticas públicas para a EI (OECD, 2017) tem sido induzido por uma visão neoliberal, pelo que as consequentes reformas estão longe de serem apenas a ordem natural das coisas.

\section{As OCEPE NO PROCESSO DE} INSTITUCIONALIZAÇÃO DA EDUCAÇÃO DE INFÂNCIA EM PORTUGAL

Em Portugal, é já no período democrático que se registam importantes mudanças no campo da EI (Folque et al., 2015; Vilarinho, 2013), sobretudo pela formalização curricular, pedagógica e simbólica que ocorre dos anos 90 em diante, fruto de fortes influências internacionais, e nas quais as Orientações Curriculares para a Educação Pré-Escolar (OCEPE, 1997, 2016 Decreto-Lei n. ${ }^{\circ}$ 147/97 e Despacho n. ${ }^{\circ}$ 9180/2016, respetivamente) constituem marcos relevantes (cf. Figura 1).

Ao concentrarmos a análise na transformação das finalidades e objetivos presentes na legislação produzida entre 1977 e 2016, destacam-se quatro grandes tendências no processo de institucionalização da EPE. A primeira, de natureza estrutural, prende-se com a extensão e

\footnotetext{
${ }^{5}$ Vários autores (Moss et al., 2016) têm vindo a assumir uma postura crítica face a este instrumento, defendendo que se as dimensões "qualidade estrutural" e "resultados" são passíveis de serem mensuráveis, o mesmo já não acontece no que se refere à qualidade do "processo" (interações dentro dos contextos, relação com famílias, papel do brincar, etc.).
}

${ }^{6}$ Consultar http://www.oecd.org/education/school/the-international-early-learning-and-child-well-being-study-the-study.htm 


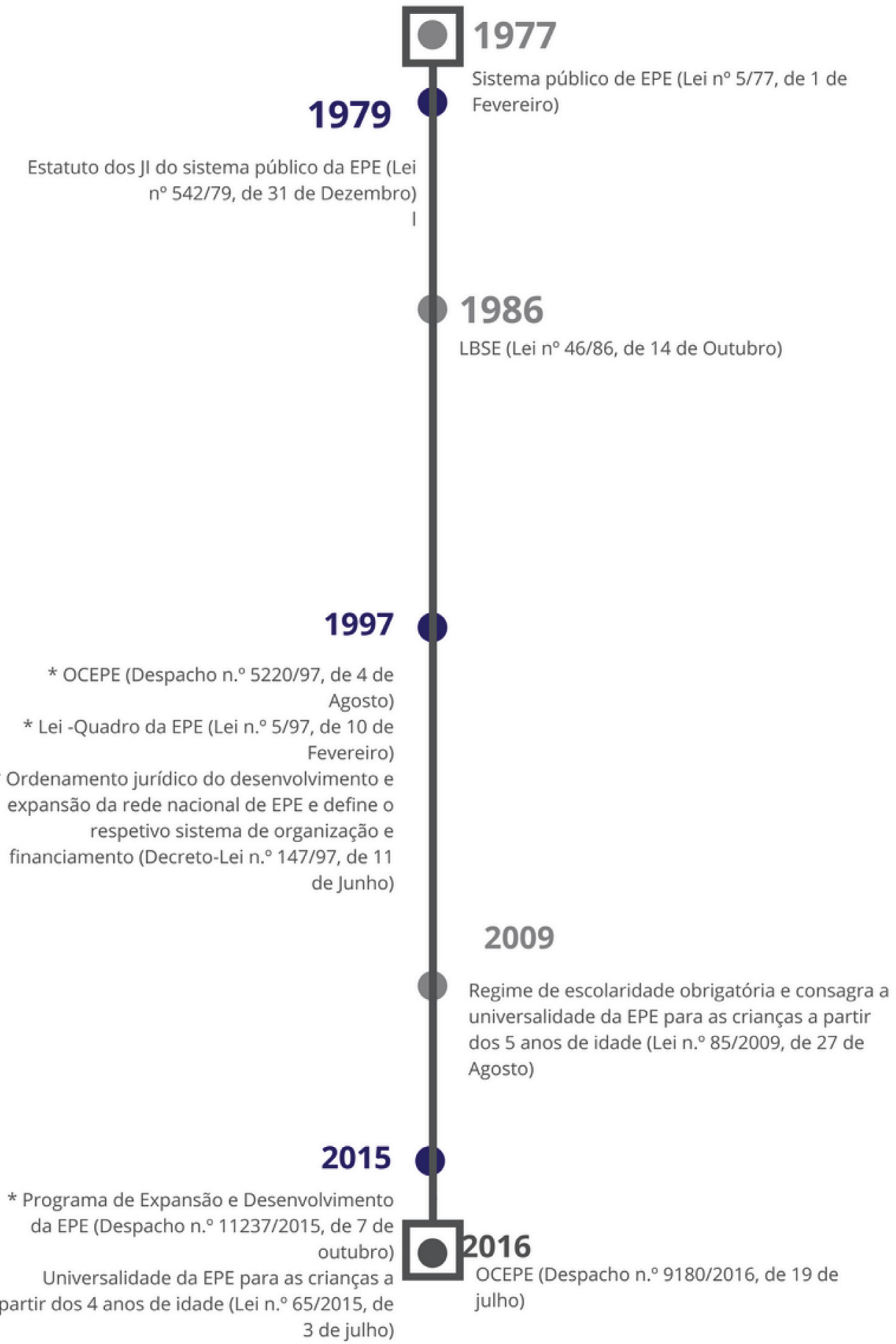

FIGURA 1. EPE - Principais marcos no calendário legislativo (Portugal 1977-2016).

consolidação da EPE numa única rede nacional de JI sob tutela do ME (Lei-Quadro da EPE Lei $\mathrm{n}^{\circ}$ 5/97, de 10 de fevereiro), deixando para a história a sua escassez e dispersão territorial (Lei $n^{\circ}$ 5/77, de 1 de fevereiro, e Lei $n^{\circ}$ 542/79, de 31 de dezembro). A segunda, de natureza socioeconómica e política, aponta para a permanência das funções compensatórias da EI para assegurarem o sucesso escolar e educativo, embora formuladas diferentemente - em 1977/79 urgia colmatar as gritantes assimetrias regionais; agora a preocupação é prevenir atempadamente o insucesso e abandono escolares, sendo mais explícita a aposta nas aprendizagens académicas 
(OCEPE, 1997, 2016). A terceira, de natureza sociopedagógica e educativa, reitera a função da EI na promoção do desenvolvimento global da criança, estando inscrita em todos os documentos sem exceção. Porém, não esclarecem suficientemente os sentidos implícitos desse desenvolvimento. A quarta, de natureza curricular, apresenta uma crescente explicitação de conteúdos ao nível dos pressupostos teóricoconcetuais, metodologias, avaliação e resultados esperados das aprendizagens (cf. OCEPE, 1997, 2016).

\section{As OCEPE (2016): ENTRE Ditos E NÃO DITOS}

Um olhar adentro pelas OCEPE de 2016 visa compreender com maior profundidade o processo de (re)institucionalização da $\mathrm{EPE}^{7}$ e avançar no esclarecimento dos sentidos das orientações e conceções de EPE centralmente definidas. Para tal, recuamos brevemente às OCEPE (1997) para relembrar: i) as finalidades que estão na sua génese - definir referenciais comuns do trabalho educativo para melhorar tanto a qualidade da EI como a tomada de decisões e a condução do processo educativo pelos/as educadores/as de infância; ii) os seus principais fundamentos teórico-metodológicos - o desenvolvimento e a aprendizagem como vertentes indissociáveis; o reconhecimento da criança como sujeito ativo das aprendizagens e a sua centralidade nos processos educativos da EPE; a construção articulada do saber; a exigência de resposta a todas as crianças; iii) a conceção de currículo - integrado, contextualizado e respeitador da individualização do ser irrepetível que é cada criança nos processos coletivos de educação que se realizam no JI; iv) a definição de três grandes Áreas de Conteúdo a serem consideradas pelos/as educadores/as de infância no planeamento da sua ação pedagógica e da avaliação das aprendizagens das crianças, aí se destacando a área da Expressão e Comunicação pelas ramificações que contempla e onde, pela primeira vez, surgem, explicitamente, referências à "Abordagem à escrita" e à "Matemática" (cf. Ferreira \& Tomás, 2016).

Duas décadas depois, a publicação das novas OCEPE (2016) foi justificada em função das mudanças sociais entretanto ocorridas na organizaçãofamiliarena parentalidade,conceções de criança e de infância, no avanço e divulgação das tecnologias, na organização e administração escolares e nos novos conhecimentos oriundos das ciências sociais e da educação. Além dos princípios e fundamentos pedagógicos já referidos (cf. pt. 2.), há um conjunto de alterações: i) o reconhecimento da educação como um contínuo desde o nascimento e a importância de haver uma unidade pedagógica para a infância, com fundamentos e princípios comuns, incluindo a educação em creche, mas sobrevindo evidentes preocupações com a preparação das crianças para a sua integração no $1^{\circ}$ CEB (cf. seção "Continuidade educativa e transições", p. 97); ii) a convocação de olhares e saberes teóricos, multirreferenciados e atualizados dos estudos da infância e dos seus direitos, e a clarificação concetual e/ou referência explícita a noções-chave como 'aprender a aprender', 'cuidar' e 'cuidado ético' e 'brincar' (secção 2.1., p. 11.); iii) a assunção da criança como sujeito e principal agente da sua aprendizagem, sublinhando o seu papel ativo e a importância da sua participação, evocando a Convenção dos Direitos da Criança (1989) (2016, pp. 9 e 106); iv) a presença de um capítulo específico e detalhado sobre "Intencionalidade educativa - construir e gerir o currículo” (2016, pp. 13-

\footnotetext{
${ }^{7}$ A partir deste ponto usaremos a nomenclatura dos documentos oficiais de Educação Pré-Escolar (EPE). Não obstante, sublinhase que EI e EPE não são sinónimos. A defesa de uma ou outra aponta para imagens, conceções e posicionamentos socioeducativos bem distintos.
} 
20); v) maior explicitação e refinamento dos domínios existentes nas Áreas de Conteúdo, pela inclusão de dois domínios na Área da Expressão e Comunicação: o da Educação Física, que se autonomizou, e o da Educação Artística, que mudou a nomenclatura dos seus subdomínios
- Artes visuais; Jogo dramático/teatro; Música; Dança; vi) a clarificação dos objetivos de desenvolvimento e das aprendizagens a promover em cada área (2016, p. 32 e cf. Quadro 1).

Referenciadas ao contexto sociopolítico e ideológico a que se reporta a produção das

\section{QUADRO 1}

\section{OCEPE 2016 - Conceções de Criança, Educação de Infância, Currículo, Pedagogia, Educador/a de Infância}

\begin{tabular}{|c|c|}
\hline Criança(s) & $\begin{array}{l}\text { "Criança como sujeito e agente - Ao ser protagonista do seu processo de desenvolvimento e aprendizagem, a } \\
\text { criança é ouvida e participa nas decisões que têm influência na sua vida e no seu mundo. Este sentimento de } \\
\text { agência faz parte da construção da sua identidade e autoestima." (p. 106) } \\
\text { "Este papel ativo da criança decorre também dos direitos de cidadania, que lhe são reconhecidos pela Convenção } \\
\text { dos Direitos da Criança (1989), a saber: o direito de ser consultada e ouvida, de ter acesso à informação, à liberdade } \\
\text { de expressão e de opinião, de tomar decisões em seu benefício e do seu ponto de vista ser considerado (p. 9). }\end{array}$ \\
\hline $\begin{array}{l}\text { Educação } \\
\text { de Infância }\end{array}$ & $\begin{array}{l}\text { "Apesar de a legislação do sistema educativo (LBSE; Lei-Quadro da EPE) incluir apenas a educação pré-escolar } \\
\text { a partir dos } 3 \text { anos, não abrangendo a educação em creche, considera-se, de acordo com a Recomendação do } \\
\text { Conselho Nacional de Educação, que esta é um direito da criança (...) são apresentados fundamentos e princípios, } \\
\text { que constituem uma base comum para o desenvolvimento da ação pedagógica em creche e em jardim de infância" } \\
\text { (p. 5) } \\
\text { "Dada a importância das primeiras aprendizagens, é atribuído à EI um papel relevante na promoção de uma } \\
\text { maior igualdade de oportunidades relativamente às condições de vida e aprendizagens futuras, sobretudo para as } \\
\text { crianças cuja cultura familiar está mais distante da cultura escolar" (p. 10) } \\
\text { "no caso da EI, não se trata de adotar na creche, com as crianças mais velhas, práticas mais adequadas ao jardim } \\
\text { de infância (tais como, tempos longos em grande grupo), nem de começar a fazer no JI atividades consideradas } \\
\text { como características do 1.o ciclo. Trata-se antes de proporcionar, em cada fase, as experiências e oportunidades de } \\
\text { aprendizagem que permitam à criança desenvolver as suas potencialidades, fortalecer a sua autoestima, resiliência, } \\
\text { autonomia e autocontrolo, criando condições favoráveis para que tenha sucesso na etapa seguinte" (p. 97) }\end{array}$ \\
\hline Currículo & $\begin{array}{l}\text { "As OCEPE não constituem um programa a cumprir, mas sim uma referência para construir e gerir o currículo" } \\
\text { (p. 13) } \\
\text { "Em educação de infância, o currículo refere-se ao conjunto das interações, experiências, atividades, rotinas e } \\
\text { acontecimentos planeados e não planeados que ocorrem num ambiente educativo inclusivo, organizado para } \\
\text { promover o bem-estar, o desenvolvimento e a aprendizagem das crianças" (p. 106) } \\
\text { Refinam-se as três áreas de Conteúdo: Formação Pessoal e Social; Expressão e Comunicação; Conhecimento } \\
\text { do Mundo, pelo desdobramento da Área da Expressão e Comunicação, nos domínios da Educação Física, da } \\
\text { Educação Artística, da Linguagem Oral e Abordagem à Escrita e da Matemática; sendo que, por sua vez, o domínio } \\
\text { da Educação Artística inclui os subdomínios - Artes Visuais; Jogo Dramático/Teatro; Música; Dança (p.31-96). }\end{array}$ \\
\hline Pedagogia & $\begin{array}{l}\text { "O tratamento das diferentes áreas de conteúdo baseia-se nos fundamentos e princípios comuns a toda a pedagogia } \\
\text { para a educação de infância, pressupondo o desenvolvimento e a aprendizagem como vertentes indissociáveis do } \\
\text { processo educativo e uma construção articulada do saber em que as diferentes áreas serão abordadas de forma } \\
\text { integrada e globalizante" (p. } 31 \text { ) }\end{array}$ \\
\hline $\begin{array}{l}\text { Educador/a } \\
\text { de infância }\end{array}$ & $\begin{array}{l}\text { "As OCEPE baseiam-se nos objetivos globais pedagógicos definidos pela referida Lei e destinam-se a apoiar a a } \\
\text { construção e gestão do currículo no JI, da responsabilidade de cada educador/a, em colaboração com a equipa } \\
\text { educativa do estabelecimento educativo/agrupamento de escolas." (p. 5) } \\
\text { "Intencionalidade educativa - construir e gerir o currículo - A ação profissional do/a educador/a caracteriza-se } \\
\text { por uma intencionalidade, que implica uma reflexão sobre as finalidades e sentidos das suas práticas pedagógicas } \\
\text { e os modos como organiza a sua ação. Esta reflexão assenta num ciclo interativo - observar, planear, agir, avaliar } \\
\text { - apoiado em diferentes formas de registo e de documentação, que permitem ao/à educador/a tomar decisóes } \\
\text { sobre a prática e adequá-la às características de cada criança, do grupo e do contexto social em que trabalha. O } \\
\text { desenvolvimento deste processo, com a participação de diferentes intervenientes (crianças, outros profissionais, } \\
\text { pais/famílias), inclui formas de comunicação e estratégias que promovam esse envolvimento e facilitem a } \\
\text { articulação entre os diversos contextos de vida da criança" (p. 5) }\end{array}$ \\
\hline
\end{tabular}


OCEPE (1997, 2016), e atentas ao argumento do consenso generalizado em torno do desígnio orientador das ações e tomadas de decisão dos/as educadores/as, consideramos que o seu conteúdo, especialmente o atual, está longe de traduzir um conjunto de informações, conceções e valores socialmente incontroversos ou neutros. Atente-se à maior explicitação na clarificação, detalhe e exemplos de processos e estratégias das aprendizagens (cf. capítulos "Intencionalidade Educativa", "Áreas de Conteúdo" ou "Continuidade Educativa e Transições", 2016, p. 32); a ilustração dos comportamentos que evidenciarão aprendizagens esperadas; e das estratégias tidas como as adequadas e o seu grau de pormenorização.

Assim sendo, em processos de transição paradigmática como o que estamos a analisar, refletir se "o pré-escolar faz a diferença" torna-se pertinente para informar uma posição crítica do conteúdo das atuais OCEPE e dos rumos que se avizinham para a EI. Duas questões se colocam. A primeira é a de saber se estaremos perante a valorização de uma conceção de criança-aluno/a e de EPE crescentemente curricularizada e escolarizada visando preparar para a entrada no $1^{\circ} \mathrm{CEB}$, ou de uma conceção de criança cujo brincar é assumido como experiência infantil presente e a respeitar, e, portanto, de uma EPE que reconhece e potencia as culturas infantis criando condições e oportunidades para o exercício da participação ativa. A segunda é a de saber perante que conceção de educador/a estaremos: com autonomia concetual, coconstrutor/a do currículo, contextualizado, flexível e não adultocêntrico? Com uma missão técnica e executiva? Com uma intencionalidade que ultrapassa os próprios objetivos das OCEPE?

Estamos, pois, perante uma nova fase da EI, contraditória, ambígua e tensa, em que se justapõem os discursos acerca das crianças e dos seus direitos e os da pedagogia, em que as crianças assumem centralidade (Vasconcelos, 2015), com os discursos da intencionalização educativa segundo a "especificação de objetivos e conteúdos com vista a melhorar a quantidade de conhecimento 'real' para tornar a componente educativa mais eficiente” (Gulløv, 2012, p. 100).

Ora, qualquer esclarecimento das tensões e dos sentidos de que se revestirão as OCEPE localmente implicará a sua interpretação pelos/as educadores/as ${ }^{8}$, de acordo com as suas próprias conceções de criança/infância, educativas, pedagógicas e curriculares, os modos como as projetaram e implementaram junto das crianças e as especificidades dos contextos e dos sujeitos. Nesta transposição das políticas para as práticas pedagógicas, prosseguimos e reiteramos uma vez mais, então, se e até que ponto "o pré-escolar faz a diferença”.

\section{FACETAS DA ESCOLARIZAÇÃO NA EDUCAÇÃO DE INFÂ NCIA}

A institucionalização da infância e crescente universalização da EPE, a que Portugal também não escapou, faz do JI um observatório privilegiado para compreender os modos como ali se (re)contextualizam os entendimentos que os/as educadores/as elaboram acerca das OCEPE e as formas práticas e simbólicas destinadas às crianças. Neste sentido, cientes e conscientes da diversidade que caracteriza as práticas pedagógicas dos/as educadores/as de infância, não podemos, no entanto, ignorar muitas outras que, não sendo necessariamente recentes $\mathrm{e}$ estando sob influência de enormes pressões sociais, têm vindo a trabalhar e trabalham em prol de uma, cada vez mais assumida, préescolarização das crianças. Analisamos agora

\footnotetext{
${ }^{8}$ Dadas as características do texto das OCEPE a que aludimos, atente-se aos casos em que educadores/as e outros/as profissionais, indo além do seu espírito, interpretam aquelas orientações como prescrições.
} 
algumas facetas dessa escolarização da EPE, transversais aos JI observados e emergentes da análise das interações entre educadoras e crianças.

\subsection{BRINCAR PARA APRENDER CONTEÚDOS}

Um grupo de rapazes brincava com carrinhos no chão. De vez em quando havia alguns "choques" entre as viaturas, mas o "trânsito" continuava a fluir sem grandes incidentes. A educadora aproximou-se trazendo uma fita adesiva e começou a colar tiras no chão, definindo "ruas"/"estradas".

... As crianças que estavam envolvidas na brincadeira começaram a dar ideias:

- Põe outra estrada aqui! - pediu V. A educadora faz uma "rua" perpendicular à "rua" principal e pergunta: - Meninos, o que está a faltar nesta pista?

- Passadeiras para as pessoas passarem - diz o B.

- E para os carros pararem? - perguntou a educadora.

- Placas! - responde o E.

- Que placas? - volta a perguntar a educadora, mas, como as crianças não respondem, ela sugere o "STOP", diz que podem ir pesquisar no computador e, de seguida, pergunta quem ia desenhar/copiar o sinal de trânsito... aos poucos, a "pista" foi ganhando outros elementos sugeridos pela educadora e pelas crianças. Pouco depois, algumas crianças começam a colocar peças de madeira na "pista" simulando "construções" que, de repente, caíam.

- Já está em obras uma estrada assim tão nova? - perguntou a educadora.

- Estamos a brincar! - respondeu o B. (Nota de campo, JIA, 2015, crianças 5 anos)

A intervenção inicial da educadora, traçando 'ruas', parecendo decorrer da observação prévia da brincadeira das crianças, apresenta-se contextualizada com o tema informalmente definido por elas nas suas ações. O 'cruzamento', podendo ser interpretado como complexificação de um traçado linear, ou acréscimo de dificuldade ao brincar em curso, depressa se converte numa espécie de lição breve de educação rodoviária, a cargo da educadora, em que a transmissão de informações sobre sinais de trânsito passou a ser o tópico a desenvolver. Expressando o lema "Brincar sim, mas com propósito", o choque entre o princípio da intencionalidade que parece animar a intervenção da educadora e o princípio do prazer que parece animar a atividade lúdica das crianças eclode quando estas passam a ressignificar as 'casas' como 'casas que caem'. O seu entendimento como sementes que lançam o caos na paisagem logo obriga a uma chamada de atenção velada, para a manutenção da ordem e da 'cidade que se tinha construído’: “- Já está em obras uma estrada assim tão nova? - perguntou a educadora”. A pronta resposta de $B$. a tal reparo mostra que as crianças, apesar da aceitação das propostas da educadora, não se subsumiram a elas nem se conformaram à sua lógica, criando entre si, ao invés, versões da realidade alternativas às dos/as adultos/as que mostram estarmos perante lógicas de sentido diferenciadas.

Neste sentido, a intervenção inicial da educadora como sendo 'amiga das crianças' pode ser vista como uma estratégia pedagógica para otimizar a aquisição de determinados conteúdos que não deve ser confundida com uma pedagogia e um currículo centrados na criança (Vasconcelos, 2015), até porque a orientação que imprime em prol das aprendizagens que contarão no seu futuro escolar se adianta ao reconhecimento dos seus interesses e competências como atores sociais no presente. 
4.2 ENQUADRAR, ADIAR, SELECIONAR E DEIXAR CAIR NO ESQUECIMENTO AS PROPOSTAS DAS CRIANÇAS

A. e L. estão na 'casa', vestindo e despindo os vestidos. A. vem para a 'pintura' a dançar ballet $\mathrm{e}$ imediatamente a educadora diz: - Já sabe que as fronteiras têm que ser respeitadas. Vá lá para a casinha fazer essas coisas, vá, andor...

R. e N. juntam-se a A. e L. e começam a conversar sobre a possibilidade de fazerem uma dança "prós outros". Riem, segredam e apontam. L. dirige-se à estagiária: - T., estamos prontos. Queres ver a nossa dança? - diz L.

- Sim, quero. Que interessante! - responde T.

L. levanta-se e começa a observar a performance. . . . T. propõe à educadora realizar um projeto sobre o ballet, e ela responde: - Acho que pode e deve avançar com a chuva de ideias amanhã, mas não vai fazer com todos. Esqueça! Os mais novos não estão 'nem aî́. Esses só querem brincar. Não estão preparados ainda! Depois, chama por L. e N. dizendo-lhes: "Vão para aquela mesa trabalhar com a T.”.

- Mas... olha... - tenta dizer A., e continua a fazer pliés.

- O melhor é sentá-los todos nas mesas e tentar fazer algo sobre o ballet - diz a educadora para a estagiária. - Bem, está na hora de pôr esta gente toda a trabalhar.

A. começa a dar pontapés nos móveis da área da casa. [O compromisso assumido nunca mais se cumpriu] (Nota de campo, JIB, 2016, crianças 3 a 5 anos)

Apesar da organização espacial dos JI apresentar, frequentemente, um enquadramento e classificação fracos, típicos das pedagogias invisíveis e de currículos de integração (Bernstein, 1982), muitas das intervenções dos/ as educadores/as, como a reportada, orientamse em sentido oposto, afirmando explicitamente uma ordem institucional que deve funcionar segundo as premissas dos currículos de coleção e das pedagogias visíveis (Bernstein, 1982); ou seja, a 'área da casa' é para brincar ao faz-deconta, mesmo que seja dançar ao ballet, e a área da pintura' é para pintar, desenhar.

Perante a chamada de atenção da educadora, as crianças, agregando mais um duo, persistem na sua intenção de "dançar ao ballet", alargando-a a uma proposta de "dança prós outros" que, 'agarrada' e ressignificada pela educadora, depressa se converte numa espécie de 'projeto à força' sobre o tema do ballet. Trata-se, agora, de compatibilizar a intencionalidade pedagógica de tornar útil, funcional e 'devidamente' enquadrada num projeto aquilo que é uma iniciativa emergente dos fazeres e dizeres das crianças quando brincam, organizando-as seletivamente por critérios etários - percebidos como indicadores das competências das crianças. "Sentá-los todos nas mesas e tentar fazer algo sobre o ballet" torna-se, assim, uma possibilidade de a educadora e a estagiária transformarem a dança, o movimento, e a iniciativa e organização das crianças numa área de conteúdo em que são privilegiadas atividades cognitivas que, ao subalternizarem os saberes prévios e a dimensão lúdica da ação coletiva em que estavam envolvidas as crianças, a ressemantizam como trabalho. A sua valorização torna-se assim numa espécie de 'pragmática pedagógica', atenuante de formas explícitas de escolarização, mas sem com isso deixar de desmobilizar a proposta infantil e de a adiar, para, no limite, a deixar cair no esquecimento.

\subsection{BRINCAR AO ${ }^{\circ}$ CICLO: PREPARAR PARA} SER ALUNO

Hoje começa a semana de 'brincar ao $1^{\circ}$ CEB', uma proposta vinda da diretora da organização, e a educadora $\mathrm{S}$. chegou mais cedo e reorganizou a sala, colocando 4 mesas, cada uma com 4 ou 5 cadeiras. 
- Bom dia, bom dia! - diz S. à medida que crianças e famílias chegam à sala.

- Ele já tem o estojo na mochila. Fomos ontem comprar. - diz o pai do M. à educadora...

- Hoje não vamos para a manta. Vão sentar-se nas cadeiras, devagar e sem arrastá-las. Não é para ir para aí [área da biblioteca]. É para ali - diz S., e aponta para as cadeiras.

Depois, S. distribui um conjunto de fichas para as crianças fazerem sobre planetas [tema do projeto que terminou na semana anterior]. As crianças estão $1 \mathrm{~h} 27$ sentadas, ora a pintar estrelas, ora a fazer conjuntos com os planetas. S. vai circulando entre os grupos e fazendo reforços positivos: - Veem? É giro! Não custa muito!

- É bué fixe! - diz M.

T., uma criança novata e o mais novo do grupo, pega na mão de S. e pergunta: - Já posso ir brincar?

S. olha rapidamente para a ficha, vai ao móvel e traz uma estrela, que coloca no bibe do T., dizendolhe: - Fizeste quase tudo bem. Podes, vai lá.

De rajada, levanta-se o grupo de crianças que estava sentado na mesa perto da porta.

- Meninos!!! Sentar, se faz favor! - reage S... [Mais um dia que as crianças não vão ao recreio] (Nota de campo, JIC, 2017, crianças 4 a 6 anos)

A metodologia de projeto - uma das recomendações das OCEPE (1997, 2016) e a sua dinamização curricular, que podem ser vistas como expressões visíveis da intencionalidade pedagógica educativa no quotidiano do JI, surgem aqui confinadas a uma "semana de brincar ao $1^{\circ}$ ciclo" que é exterior e superiormente definida pela direção do JI. Porém, a transformação da sala do JI numa sala de aula, das crianças em alunos/as e do grupo numa turma, da educadora numa professora que dá ordens, prescreve trabalho (fichas), avalia e recompensa ou sanciona, do brincar num trabalho sem escolha e sem que se perceba qualquer participação das crianças desvirtua, quer os propósitos da metodologia de projeto (cf. Vasconcelos, 1998) quer o brincar - a conversão do "brincar ao $1^{\circ} \mathrm{CEB}$ " numa realidade tão real por parte da educadora e de algumas famílias parece não ter deixado espaço às crianças para agirem 'como se'. Ao mesmo tempo, este projeto revela-se aqui ao serviço da fabricação de corpos dóceis, ajustados e produtivos (Foucault, 2009). Esta "arte do adestramento" (Foucault, 2009), acompanhada de estímulos positivos e de prémios - estrela no bibe -, e desdramatização do esforço de contenção - "Veem? É giro! Não custa muito!" - atesta, assim, uma visão adultocêntrica e adulterada da modalidade de projeto como trabalho pedagógico, que supõe um processo curiosamente participado com/entre crianças e adultos/as, situado e ampliador de múltiplos reportórios, abrindo-se à vivência de práticas mais democráticas.

Após avaliação positiva do trabalho realizado, a educadora condescende ao pedido “- Já posso ir brincar?” esclarecendo uma diferença entre trabalhar e brincar, entre atividades sérias e profanas. Sérias porque úteis e propedêuticas à aprendizagem dos comportamentos - estar sentado à mesa, uso das materialidades escolares (papéis, canetas, fichas) e das formas escriturais que configuram uma socialização para o modo escolar. Profanas porque, reportadas ao brincar, mostram-no como atividade remanescente, recompensa condicionada pelo bom cumprimento do trabalho sério, como castigo ou sanção, ou ainda como atitude de condescendência seletiva em função das idades infantis. Por conseguinte, familiarizar as crianças com as práticas normativas da escola básica torna-se sinónimo de alunização (Correia \& Matos, 2001; Matos, 2011), ou seja, de uma socialização precoce para o desempenho do papel de aluno/a (Perrenoud, 1995). Perante esta transformação do JI em escola, urge refletir criticamente: em que medida "o pré- 
escolar faz a diferença" da escola do $1^{\circ}$ CEB?

$\begin{array}{lrrr}4.4 & \text { APRESENTAR } & \text { RESULTADOS } \\ \text { COMO EVIDENCIAS DE } & \text { COMPETENCIAS } \\ \text { ADQUIRIDAS } & & \end{array}$

C. pede às crianças para se sentarem na mesa e fazerem o desenho relativamente à visita do apicultor à sala, no âmbito do projeto das abelhas. M. anda pela sala e senta-se no sofá que está na área da casa.

- Anda sentar-te e trabalhar, L. Nunca queres fazer nada - diz-lhe a auxiliar.

M. chama S. para brincar com ele, mas ela não responde... Já na mesa, L. diz a C. que o desenho já está pronto e pergunta se pode ir brincar. C. olha para o desenho e volta a colocá-lo na mesa.

- Mas as abelhas são verdes? - pergunta C.

- Sim - responde L.

Gera-se uma discussão com as crianças que estão na mesa acerca das cores das abelhas.

- Além de estar mal... são amarelas e pretas, como a 'abelha Maya'. Ainda faltam aqui coisas. Onde está o apicultor? O Sr. João, que esteve aqui há pouco? - questiona $\mathrm{C}$.

- Não está... foi almoçar! - diz o L., e aponta para o desenho fazendo um gesto como que indicando a 'saída da figura' com o dedo. (Nota de campo, JID, 2016, crianças 4-6 anos)

A solicitação de produções gráficas relativas às atividades desenvolvidas, podendo ser justificada como registo de memórias significativas que contam histórias do grupo e do indivíduo, pelo seu grau de recorrência, vulgarização e visibilidade dentro e fora da sala, e na instituição, pode ser igualmente entendida quer como uma forma de evidenciar e de legitimar o trabalho pedagógico desenvolvido pelo/a educador/a com as crianças, quer como uma suposta evidência do nível de desempenho que vai sendo atingido pelas mesmas. Isso significa que as produções das crianças se assumem como 'prova' das suas aprendizagens e dos seus progressos. Significa, também, que os cuidados colocados no resultado final destas produções são, porventura, mais vigiados e controlados pela educadora, e que as apreciações suscitadas durante o processo da sua concretização e o resultado final se assumem como facetas da avaliação na EI, entre outras. Tal como a situação acima mostra, a explicitação das regras, preceitos, conceitos e convenções sociais tende a ser objeto de forte regulação, o mesmo acontecendo com as chamadas de atenção para a conformidade das crianças à 'completude' de uma dada realidade, decorrente do preenchimento das 'falhas' detetadas - "Ainda faltam aqui coisas. Onde está o apicultor?" -, e para a correção dos erros - "Mas as abelhas são verdes?".

A ludicidade, sendo por definição uma atividade autotélica, autodeterminada e livre (Brougère, 1998), não pressupõe necessariamente nem a realização de produtos finais, nem a sua divulgação, nem a sua avaliação, o que torna invisível, de alguma forma, quer o 'trabalho das crianças', se concebermos que o seu oficio é brincar (Chamboredon \& Prévot, 1973), quer, por consequência, a tal intencionalidade que é suposto estar presente na ação das/os educadoras/es. Lidar com esta invisibilidade torna-se mais agudo quando vivemos num contexto, como aquele que já referimos, em que as performances das crianças, mesmo as mais pequenas, começam a ser exigidas, ainda que implícita e informalmente.

\footnotetext{
${ }^{9}$ Série infantil criada por Waldemar Bonsels em 1912. Estreou em Portugal em 1978.
} 


\section{CONSIDERAÇÕES FINAIS}

O processo de institucionalização da EI em Portugal, nos últimos 30 anos, tem vindo a desenhar uma trajetória em que o acúmulo de saberes e conteúdos disciplinares centrados numa transmissão didática, padronizada e uniformizadora, de tipo individualizado, parece ter em mira a aquisição de aprendizagens formais e de competências escolares. Esta trajetória, frequentemente justificada em nome da qualidade e da necessidade de intervir atempadamente para prevenir o abandono e o insucesso escolar, antecipa já na EI facetas da recontextualização local de políticas transnacionais que eram apenas visíveis para/nos níveis educativos mais avançados. Trata-se da promoção cada vez mais precoce da literacia, numeracia, tecnologias, cientificismo e poliglotismo, exercitados pelo uso intensivo de manuais de tipo escolar e/ou de propostas de atividades apostadas na transmissão de conteúdos escolares. As lógicas subjacentes a práticas pedagógicas orientadas segundo os princípios "Brincar para aprender conteúdos", "Enquadrar, adiar, selecionar e deixar cair no esquecimento as propostas das crianças", "Brincar ao $1^{\circ}$ ciclo: preparar para ser aluno/a" e "Apresentar resultados como evidências de competências adquiridas" constituem manifestações de algumas das tensões e ambiguidades que mais frequentemente observámos nos JI. Tais tensões parecem ficar a dever-se à existência de um quadro teórico e ideológico que aponta para uma conceção de criança como ator social, produtora de cultura e sujeito de direitos, incluindo o de brincar, como aparece plasmado nas OCEPE (2016), e de práticas pedagógicas que, parecendo atribuir centralidade ao que as crianças dizem e fazem como alicerce da intencionalidade pedagógica, denotam, afinal, preocupações de tipo transmissivo em função dos níveis de desenvolvimento da criança 'clássica', por estádios, supostamente objetivados pelas idades, através de estratégias de organização espácio-temporais e materiais uniformes, em que o/a educador/a tanto cria condições para que determinadas aprendizagens ocorram 'espontaneamente' como para que ele/a próprio/a ministre conteúdos.

Posto isto, então de que estamos a falar quando equacionamos a pergunta "O pré-escolar faz a diferença?"? Estando cientes de que a realidade na EI é mais complexa e diversa, ali coexistindo práticas pedagógicas heterogéneas e até de resistência ao modelo escolocentrista (Correia \& Matos, 2001), as mudanças sociais e de política educativa a que fizemos alusão parecem expressar uma nova forma de (re)institucionalização da infância e da sua educação, cujas implicações nas práticas pedagógicas, como procurámos mostrar, sugerem a pertinência de se proceder a um debate e aprofundamento em torno de várias questões que precisam ser cuidadosamente refletidas para uma EI capaz de fazer a diferença.

Uma delas refere-se à pedagogia da EI e à sua especificidade, ou não: por um lado, entre os princípios de uma pedagogia contextualizada e praxiológica (Rocha, Lessa, \& Buss-Simão, 2016) que reconhece a centralidade da criança (Vasconcelos, 2015), não a isolando do todo social, e do papel do/a educador/a enquanto dinamizador/a de um currículo coconstruído com as crianças, no reconhecimento dos seus saberes e experiências prévias, bem como das suas culturas infantis. Por outro lado, outras pedagogias orientadas por objetivos prédefinidos e conteúdos pré-programados e homogéneos que instrumentalizam os desejos de saber das crianças e convertem as suas ações em estratégias funcionais, supostamente "lúdico-pedagógicas" (Brougère, 1998) e 'amigas das crianças', para transmitirem conteúdos e promoverem aprendizagens de comportamentos considerados úteis e necessários às etapas seguintes do seu percurso escolar e de vida. Perante tais contrastes, urge repensar a seleção e intencionalidade dos espaços e materiais 
pedagógicos.

Uma outra questão refere-se à importância da atividade lúdica na $\mathrm{EI}$, ou não, dada a pressão que tem vindo a ser exercida sobre os/ as educadores/as para prestarem contas do trabalho que realizam com as crianças, e em que as produções destas constituem duplas provas materiais: da eficácia, eficiência e produtividade do trabalho pedagógico desenvolvido e do nível das competências adquiridas por aquelas. Não será por acaso que as crianças brincam cada vez menos e por menos tempo no JI e, quando o podem fazer entre elas, tal deverá respeitar as regras dos/as adultos/as, decorrer com ordem e segurança e assumir uma inteligibilidade imediatamente acessível aos seus olhos. Brincar no JI é cada vez mais sinónimo ora de sanção das transgressões, ora de recompensa, ora de estratégia de ensino, como procurámos mostrar na análise de situações observadas.

Finalmente, outra questão refere-se à função do JI e ao posicionamento dos/as educadores/ as. Consideramos que o JI é um contexto de preparação para a entrada no $1^{\circ} \mathrm{CEB}$ ou deve, antes, ser entendido como mais um mundo de vida das crianças, em que estas devem ter oportunidade de potenciar as suas capacidades no presente e num contexto coletivo de partilha? Consideramos que o/a educador/a deve ser um/a especialista nas didáticas e estar preocupado/a com os resultados dos conteúdos aprendidos pelas crianças ou deve ser, antes, um/a especialista dos mundos sociais e culturais infantis, em particular das culturas lúdicas, para ficar capacitado/a a ler as diversas aprendizagens sociais e culturais em contexto, e na sua mútua articulação, de modo a contribuir para a sua expansão? Consideramos que o conhecimento das crianças é evidenciado pelo uso intensivo de fichas e manuais ou por processos que recorrem a diversas estratégias metodológicas para documentar os saberes em uso pelas crianças e o seu desenvolvimento?

Defender que o JI é um locus de educação e de cidadania (Vasconcelos, 2007) implica a ousadia de reinventar práticas sociais, culturais, educativas e pedagógicas pelo exercício de múltiplas imaginações: além da imaginação pedagógica (Rocha et al., 2016), a epistemológica e a democrática (Santos, 2006). Uma imaginação pedagógica alimentada por saberes e experiências infantis desafiadores de modelos e práticas standard. Uma imaginação epistemológica complexa na análise da EI que inclui a multirreferencialidade teórico-pedagógica e reflexividade crítica acerca das práticas. Uma imaginação democrática que valoriza a vida coletiva em sociedade e não abre mão da participação influente das crianças nas decisões quotidianas do JI, numa ordem negociada entre adultos/as e crianças que contribui para combater situações e relações de desigualdade e exclusão. Talvez assim se possa caminhar para uma EI que faz a diferença.

\section{REFERÊNCIAS}

Ball, S. (2011). Diretrizes políticas globais e relações políticas locais em educação. Currículo Sem Fronteiras, 1(2), 99-116.

Bassok, D., Latham, S., \& Rorem, A. (2016). Is kindergarten the new first grade? AERA Open, 1(4), 1-31. doi:10.1177/2332858415616358

Bernstein, B. (1982). A educação não pode compensar a sociedade. In S. Grácio, \& S. Stoer (Orgs.), Sociologia da educação II (Antologia). A construção social das práticas educativas (pp. 19-31). Lisboa: Livros Horizonte.

Brougère, G. (1998). A criança e a cultura lúdica. Revista da Faculdade de Educação, 24(2), 103116. doi:10.1590/S0102-25551998000200007

Chamboredon, J. C., \& Prévot, J. (1973). Le "métier d'enfant" - Définition sociale de la prime enfance et fonctions différentielles de l'école maternelle. Revue Française de Sociologie, XII(7), 295-335.

Correia, J. A., \& Matos, M. (2001). Da crise da escola ao escolocentrismo. In S. 
Stoer, L. Cortesão, \& J. A. Correia (Dir.), Transnacionalização da educação. Da crise da educação à educação da crise (pp. 91-117). Porto: Afrontamento.

European Commission/EACEA/Eurydice (2016). Structural indicators on early childhood education and care in Europe - 2016. Eurydice Report. Luxembourg: Office of the European Union.

Ferreira, M., \& Tomás, C. (2017a). “Já podemos ir brincar?” - A construção social da criança como aluno/a no jardim de infância. In I. Cortesão, L. Dornelles, N. Fernandes, M. Ferreira, I. Neves, P. Pequito,...E. Vilarinho (Eds.), Travessias e travessuras nos Estudos da Criança. Atas do III Simpósio Luso-Brasileiro em Estudos da Criança (pp. 445-455). Porto: ESEPF.

Ferreira, M., \& Tomás, C. (2017b). A educação de infância em tempos de transição paradigmática: Uma viagem por discursos políticos e práticas pedagógicas em Portugal. Cadernos de Educação de Infância, 112, número especial, 19-33.

Folque, M. A., Tomás, C., Vilarinho, M. E., Santos, L., Homem, L., \& Sarmento, M. J. (2015). Pensar a educação de infância e os seus contextos. In M. Silva (Ed.), Pensar a educação: Temas sectoriais (pp. 9-46). Lisboa: Educa.

Foucault, M. (2009). Vigiar e punir. São Paulo: Editora Vozes.

Garnier, P. (2016). Sociologie de lécole maternelle. Paris: PUF.

Gulløv, E. (2012). Kindergartens in Denmark: Reflections on continuity and change. In A. Kjørholt \& J. Qvortrup (Eds.), The modern child and the flexible labour market. Early childhood education and care (pp. 90-107). London: Palgrave MacMillan.

Halldén, G. (2012). Children's sense of place: Aspects of individualization, flexibility and free choice within the preschool context. In A. Kjørholt \& J. Qvortrup (Eds.), The modern child and the flexible labour market. Early childhood education and care (pp. 186-202).
London: Palgrave MacMillan.

Harms, T., Clifford, R., \& Cryer, D. (1998). Early childhood environment rating scale. New York: Teachers College Press.

James, A., \& Prout, A. (1990). Constructing and reconstructing childhood. Contemporary issues in the sociological study of childhood. London: Falmer Press.

Kjørholt, A., \& Seland, M. (2012). Kindergarten as a bazaar: Freedom of choice and new forms of regulation. In A. Kjørholt, \& J. Qvortrup (Eds.), The modern child and the flexible labour market. Early childhood education and care (pp. 168-221). London: Palgrave MacMillan.

Lima, L. (2017). Aprender para ganhar, conhecer para competir. Sobre a subordinação da educação na "sociedade de aprendizagem". São Paulo: Cortez Editora.

Losso, C., \& Marchi, R. (2011). A construção social do "ofício de aluno" na educação infantil. Atos de Pesquisa em Educação, 6(3), 603-631.

Matos, M. (2011). Trabalho escolar e a alunização da educação. A Página da Educação, 193, 1819.

Moss, P. (2015). Childhood, education and society at a time of deepening multiple crises. Investigar em Educação, II(4), 9-24. Disponível em https://tinyurl.com/y8v37hgh

Moss, P., Dahlberg, G., Grieshaber, S., Mantovani, S., May, H., Pence, A.,...Vandenbroeck, M. (2016). The Organisation for Economic Cooperation and Development's international early learning study: Opening for debate and contestation. Contemporary Issues in Early Childhood, 17(3), 343-351.

Motta, V. (2012). Ideologia do capital social: Atribuindo uma face mais humana ao capital. Rio de Janeiro: EdUERJ.

O pré-escolar faz a diferença? (2016). Revista Visão, 26 de março. Disponível em http:// visao.sapo.pt/actualidade/sociedade/2016-0326-O-pre-escolar-faz-a-diferenca-

OECD. (2017). Starting strong 2017. Key indicators on early childhood education and care. Paris: OECD. Disponível em http://www. 
oecd.org/education/starting-strong-20179789264276116-en.htm

ONU (1989). Convenção Internacional sobre os Direitos da Criança. Nova Iorque: ONU. Disponível em https://www.ohchr.org/en/ professionalinterest/pages/crc.aspx

Otterstad, A., \& Braathe, H. (2016). Travelling inscriptions of neo-liberalism in Nordic early childhood: Repositioning professionals for teaching and learnability. Global Studies of Childhood, 6(1), 80-97. doi:10.1177/2043610615627927

Perrenoud, P. (1995). Ofício de aluno e sentido do trabalho escolar. Porto: Porto Editora.

Rocha, E., Lessa, J., \& Buss-Simão, M. (2016). Pedagogia da infância: Interlocuções disciplinares na pesquisa em educação. $D a$ Investigação às Práticas, 6(1), 31-49.

Sahlberg, P. (2010). Rethinking accountability in a knowledge society. Journal of Educational Change, 11(1), 45-61. doi:10.1007/s10833008-9098-2

Santos, B. S. (1991). A transição paradigmática: Da regulação à emancipação. Oficina do CES, 25, 1-36. Disponível em http://www.ces.uc.pt/ publicacoes/oficina/ficheiros/25.pdf

Santos, B. S. (2006). A gramática do tempo. Para uma nova cultura política. Porto: Afrontamento.

Stoer, S. (2002). Educação e globalização: Entre regulação e emancipação. Revista Crítica de Ciências Sociais, 63, 33-45. Disponível em https://tinyurl.com/y7pf3vjv

UNESCO. (2015). Investing against evidence. The global state of early childhood care and education. Paris: UNESCO.

Vasconcelos, T. (1998). Qualidade e projeto na educação pré-escolar. Lisboa. Ministério da Educação, Departamento de Educação Básica.

Vasconcelos, T. (2007). A importância da educação na construção da cidadania. Saber(e) Educar, 12, 109-117. Disponível em http://hdl. handle.net/20.500.11796/714

Vasconcelos, T. (2015). Do discurso da criança "no" centro à centralidade da criança na comunidade. Investigar em Educação, II(4), 25-42. Disponível em http://pages.ie.uminho. pt/inved/index.php/ie/article/view/96/95

Vilarinho, M. E. (2013). O direito das crianças à educação pré-escolar pública de qualidade: Análise crítica da implementação de um modelo de educação e cuidado infantil em Portugal. Revista Pedagógica, 15(31), 281-300.

\section{LEGISLAÇÃ O CONSULTADA}

Decreto-Lei n. ${ }^{\circ}$ 147/97. Homologa as Orientações Curriculares para a Educação PréEscolar (OCEPE). Diário da República - I Série-A, N. ${ }^{\circ} 133$, de 11 de junho. Disponível em https://www.dge.mec.pt/sites/default/files/ EInfancia/documentos/28282834.pdf

Despacho n. ${ }^{\circ}$ 9180/2016. Homologa as Orientações Curriculares para a Educação PréEscolar (OCEPE). Diário da República - 2a Série, N. ${ }^{\circ}$ 137, de 19 de julho. Disponível em https://dre.pt/application/file/74981174 


\section{"DOES PRESCHOOL MAKE A DIFFERENCE?" EDUCATIONAL POLICIES IN EARLY CHILDHOOD EDUCATION AND PEDAGOGICAL PRACTICES}

\section{Abstract}

The identification of sociopedagogical practices tendentially reproductive of schooling forms, and the presence of collection curricula and formal modes of pedagogical transmission emphasizing literacy, numeracy and science point to the reconfiguration of Early Childhood Education as a context of schoolarisation and of early processes of children becoming pupils and as a socioeducational prevention strategy against school failure. From an interdisciplinary matrix between Sociology of Childhood, Sociology of Education and Educational Sciences it is analysed the trend of the recent Early Childhood Education political changes in international and national contexts, back to the $90 \mathrm{~s}$, and some of its effects on pedagogical practices. The reconstitution of this path rests on the critical analysis of official documents, namely the new Early Childhood Curriculum Guidelines (2016), and observations conducted in Portuguese kindergartens, public and private, between 2015 and 2017.

KeYwORDS: Early childhood education; Education policies; Pedagogical practices; Early childhood education curriculum guidelines

$\begin{array}{lrrr}\text { “ ¿EL } & \text { PREESCOLAR } & \text { HACE } & \text { HA } \\ \text { DIFERENCIA? } & \text { LAS } & \text { POLÍTICAS } \\ \text { EDUCATIVAS } & \text { EN } & \text { LA } & \text { EDUCACIÓN } \\ \text { INFANTIL Y PRÁCTICAS PEDAGÓGICAS }\end{array}$

\section{RESUMEN}

La identificación de prácticas socio pedagógicas tendencialmente reproductoras de la forma escolar, y de currículos de colección y modos de transmisión pedagógica formales que enfatizan la alfabetización, la numeración y la ciencia apuntan a la reconfiguración de la Educación Infantil como contexto de creciente escolarización y alunización precoz de los niños y niñas y como estrategia de prevención socioeducativa del fracaso escolar. En la interlocución entre Sociología de la Infancia, Sociología de la Educación y Ciencias de la Educación, se analiza el rumbo de los recientes cambios políticos de la Educación de Infancia en el marco internacional y nacional, retrocediendo a los años 90, y algunos de sus efectos a nivel de las prácticas pedagógicas. La reconstitución de este trayecto se basa en el análisis crítico de documentos oficiales, en particular las nuevas Directrices Curriculares para la Educación Preescolar (2016), y de observaciones realizadas en Centros de Educación Infantil, públicos y privados, entre 2015 y 2017, en Portugal.

Palabras Clave: Educación infantil; Políticas educativas; Prácticas pedagógicas; Orientaciones curriculares para la educación preescolar

\footnotetext{
${ }^{1}$ Universidade do Porto, Faculdade de Psicologia e de Ciências da Educação \& Centro de Investigação e Intervenção Educativas (CIIE), Portugal. Orcid: 0000-0003-4512-166

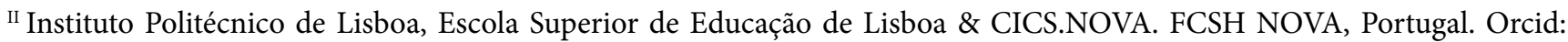
0000-0002-9220-964X
} 